\title{
O DILEMA DO PORCO-ESPINHO: COMO ENCARAR A SOLIDÃO
}

\author{
EL DILEMA DEL ERIZO: CÓMO ENFRENTAR LÁ SOLEDAD
}

THE HEDGEHOG DILEMMA: HOW TO FACE LONELINESS

\author{
Sandra POTTMEIER ${ }^{1}$ \\ Caique Fernando FISTAROL ${ }^{2}$ \\ Marta Helena Cúrio de CAETANO ${ }^{3}$ \\ Lais Oliva DONIDA ${ }^{4}$
}

O dilema do porco-espinho: Como encarar a solidão é uma obra disposta em 192 páginas, lançada em 2018 pela Editora Planeta. Escrita por Leandro Karnal, historiador graduado pela Universidade do Vale do Rio dos Sinos e doutor em História Social pela Universidade de São Paulo, professor no departamento de História pelo Instituto de Filosofia e Ciências Humanas da Universidade Estadual de Campinas, o manuscrito conduz o leitor à reflexão acerca do tema que ainda é um dilema para o ser humano: viver solitariamente ou coletivamente? Conviver no calor dos grupos e correr o risco de ser machucado pelos espinhos do outro ou viver isoladamente no frio da solidão, correndo o risco de destruir a “estabilidade humana"? (KARNAL, 2018, p. 12).

A obra é constituída por seis capítulos, incluindo ainda a introdução, conclusão e agradecimentos.

Trata-se de uma produção pessoal voltada a qualquer público interessado pela temática, especialmente a todos aqueles e aquelas que buscam compreender as relações humanas eu-outro, outro-eu (BAKHTIN, 2011; BAKHTIN; VOLÓCHINOV, 2017) e os tensionamentos gerados nessas interações, aqui sendo significada na introdução a partir da figura metafórica do porco-espinho, de Arthur Schopenhauer. Karnal, assim, tece suas impressões acerca da imersão da vivência coletiva e solitária do ser humano, embasando-se

\footnotetext{
${ }^{1}$ Universidade Federal de Santa Catarina (UFSC), Florianópolis - SC - Brasil. Doutoranda no Programa de PósGraduação em Linguística. ORCID: https://orcid.org/0000-0001-7328-8656. E-mail: pottmeyer@gmail.com ${ }^{2}$ Secretaria Municipal de Educação de Blumenau (SEMED), Blumenau - SC - Brasil. Coordenador de Línguas Estrangeiras - Línguas Alemã e Inglesa e do Ensino Bilíngue Municipal. Mestrado em Educação (FURB). ORCID: https://orcid.org/0000-0001-7650-7324.E-mail: cfersf@gmail.com

${ }^{3}$ Universidade Regional de Blumenau (FURB), Blumenau - SC - Brasil. Doutoranda no Programa de PósGraduação em Educação. ORCID: https://orcid.org/0000-0002-6247-2463. E-mail: mhelenacc@gmail.com ${ }^{4}$ Universidade Federal de Santa Catarina (UFSC), Florianópolis - SC - Brasil. Doutoranda no Programa de PósGraduação em Linguística Aplicada (UFSC). ORCID: https://orcid.org/0000-0003-3508-7030. E-mail: lais.donida@gmail.com
} 
em ancoragens filosóficas e históricas, em recortes extraídos da Bíblia, romances, obras de arte, dentre outras fontes de pesquisa, que o ser humano, na atualização do porco-espinho, é gregário, é social. Deste modo, “[...] nossos problemas também derivam disso. Tudo de bom e de ruim vem do jogo de contrastes entre companhia e solidão" (KARNAL, 2018, p. 15). Esse excerto implica na ponderação de que o homem sobreviveu/sobrevive com seus pares porque aprendeu a se constituir no/pelo outro, em uma relação mútua, resultado de um trabalho cooperativo e colaborativo em equipe.

No capítulo 1, intitulado Não é bom que o homem esteja só, Karnal discorre acerca da solidão que pode acometer o ser humano quando está sozinho ou quando está convivendo com seu par, em grupo. Tal sensação e/ou sentimento de sentir-se só se efetiva na/pela consciência do ser humano em/na relação ao outro, deste semelhante a si. Narra Karnal (2018) sobre o mundo bíblico a partir da figura de Adão que vivia solitário no paraíso, homem criado à imagem e semelhança de Deus. Adão não tinha esta consciência, pois antes nunca tivera experenciado a convivência coletiva, com o outro. Essa ausência da convivência com o outro só se constitui a partir da relação de interação, quando há de fato a vivência social, por entender-se que os seres humanos são gregários. Nas palavras de Cortella (2014, p. 24), precisamos viver congregados, uma vez "[s]omos um animal frágil, e a nossa fragilidade é tão grande que nós temos de viver juntos o tempo todo para termos força".

Entretanto, problematiza Karnal (2018) no tocante à solidão acompanhada, ou a solidão sem a presença de outra pessoa, instigando o leitor a refletir o que seria mais cruel: viver solitariamente acompanhado ou coletivamente solitário? Como seres humanos, só nos enxergamos e em grupo nos compreendemos? Tal dilema reforça a importância do diálogo, seja ele para consigo mesmo em momentos mais solitários ou na dialogia com nossos pares. Ou seja, mesmo estando ou vivendo a solidão, há dialogia, que é esse movimento de interação que só existe na e pela linguagem, a partir do social, da história, da cultura (BAKHTIN, 2011; BAKHTIN; VOLÓCHINOV, 2017).

O capítulo 2, intitulado $A$ solidão entre milhões: redes e mundo virtual, apresenta uma tessitura de reflexões acerca das mudanças dos meios de comunicação desde as gerações anteriores, conhecida por baby boomers (compreendendo os nascidos logo após a II Guerra Mundial até meados de 1960) que tiveram a televisão como expressiva tecnologia propulsora de comportamentos. A geração X (a dos nascidos de meados da década de 1960 até 1970), que viu a internet surgir, entretanto, não a utilizou em seu dia a dia. A geração Y (os que nasceram nos anos de 1980 a 1990), "nasceu sem a rede, mas a incorporou no seu cotidiano ainda muito jovem ou no início da vida adulta, fosse em casa, fosse no trabalho" (KARNAL, 
2018, p. 35). Do período compreendendo a década de 1990 e anos 2000, surge a geração Z, também conhecida por nativos digitais (PRENSKY, 2001), geração esta que nasceu e cresceu na era digital e conectada, a qual compreendem uma vida com internet. Na mesma direção e vislumbrando uma relação bem mais próxima do uso de diferentes recursos semióticos, multimodais, emerge a geração Alpha (constituída por crianças nascidas a partir dos anos 2010 até o presente). Diferenciam-se, portanto, das gerações baby boomers, X, Y, sendo as pessoas inscritas nestas gerações, conhecidas como imigrantes digitais (PRENSKY, 2001). Essas mudanças de comportamento provocadas agora a partir das mídias sociais, que atravessaram e ainda atravessam as gerações, implicam pensar, conforme aponta Karnal (2018), na solidão, no isolamento e na felicidade que repercutem e incutem tais ações humanas na/pela relação e mediação com o outro. Karnal (2018) discorre ainda sobre como esses comportamentos, em que medida e de que maneira, transformaram o ser humano inscrito no século XXI, o qual pode sentir-se solitário, isolado ou (in)feliz a partir da configuração digital que ora se apresenta na sua vida diária, seja ela voltada para quaisquer esferas de atividade humana: familiar, religiosa, do labor, entre outras. O autor assinala que a internet trouxe mais autonomia para as pessoas, entretanto, também serviu para "reafirmar o self", ou seja, criou "a ilusão da companhia, o vício da curtida" (KARNAL, 2018, p. 46, grifos do autor).

Assentado no sociólogo David Riesman, autor da obra "A multidão solitária", Karnal (2018) aponta que na geração baby boomer (a geração da guerra), os filhos eram influenciados pela família, pela figura do pai ou da mãe, ou ainda de autoridades mais velhas/experientes e acabavam, desta maneira, reproduzindo comportamentos, padrões de vida. Nessa época, as pessoas "dependiam” da aprovação de seus pais/autoridades no que diz respeito às suas condutas, atitudes, modos de ser, de agir, de pensar A partir do pós-guerra afloram os meios de comunicação em massa. Assim, com um "novo padrão comportamental, os indivíduos passavam a depender cada vez mais da aprovação de seus pares, nas mídias sociais, para viverem: "As pessoas perdem a liberdade social e a autonomia individual tentando ser como as outras" (KARNAL, 2018, p. 47).

Estas tentativas de seguir um padrão, um modelo, para se tornar igual ao outro, acaba refletindo nas relações sociais que se constroem a partir da interação com o outro, uma relação que muitas vezes se ampara mais no virtual/digital do que no real. Isto, pois, o mundo virtual/digital traz um certo controle do sujeito desse/nesse "filtro bolha" que impede o ser humano de sentir dor, insegurança, de se sentir infeliz. A dor faz amadurecer, crescer, ensina a conviver e a curar os espinhos que machucam e os quais também machucamos o outro. "Na 
dor encontro algo novo, um limite, um conhecimento a mais, o grão de areia que a ostra pode transformar em pérola" (KARNAL, 2018, p. 50).

Diferentemente do que ocorre, quando as pessoas se lançam para o abismo virtual/digital, ao se projetarem naquilo que buscam e desejam ser e ter, a partir de um universo que é possível obter e que também se pode evitar a dor, há a criação de uma nova identidade formada/constituída a partir de um avatar (um cibercorpo), inscrito em distintos ciberespaços, como as redes sociais, jogos virtuais/digitais, sites de relacionamento (KARNAL, 2018). Assim, cada vez mais há um isolamento que restringe o toque, o cheiro, entre tantos outros sentidos e sentimentos, em que não se experimenta o que é diferente, o que é externo a nós, o outro. Para além disso, pode-se permitir a reflexão acerca do atual contexto, em virtude da pandemia do Covid-19, que intensificou o isolamento devido às medidas de controle sanitário, mas também ocasionou uma restrição do outro e de nós mesmos.

Assim, (com)viver com o outro em meio à heterogeneidade de perfis, de identidades, é tomar consciência de si e do outro, é dialogar, é trocar, negociar, constituir-se enquanto ser humano por essas relações dialógicas (BAKHTIN, 2011). Para Karnal (2018, p. 54), “[a] solidão pode ser boa e produtiva, tranquilizadora e até essencial" ao passo que eu consigo tirar proveito dela, refletindo sobre si/mim, "me sentindo acompanhado sem estar com ninguém”.

O capítulo 3, intitulado Solidão, solitude e livros, envolve o leitor a partir das interlocuções empreendidas por Karnal (2018, p. 88, acréscimos nossos) quando o autor traz à tona as "[d]ezenas e dezenas de vidas solitárias [que] estão nas páginas da literatura". Histórias que refletem e refratam diferentes contextos de vivência e das condições de produção de autores/as no que se refere à solidão e ao isolamento. "Isolamentos conscientes, impostos, vingativos, reflexivos, produtivos, enlouquecedores, desafiadores e todas as possibilidades que você conseguir imaginar" (KARNAL, 2018, p. 88). Narrativas estas que se (entre)laçam em diferentes (entre)lugares de isolamento e solidão, que vão desde a exposição do isolamento do britânico Andrew Wiles a fim de encontrar o erro no Teorema de Fermat, perpassando pelos personagens de Macbeth e Hamlet de Shakespeare; por Dom Quixote de Cervantes; ao romance de Defoe "Robinson Crusoé", a expressividade na literatura por escritoras como Heloísa Argenteuil, Hypatia de Alexandria, Kate Chopin, Charlotte Anna Perkins, Virginia Woolf, os/as quais são descritos por Karnal (2018).

Nas, pelas e com as distintas histórias de vida destes e de outros personagens, concorda-se com Karnal (2018, p. 60) quando afirma que: "A literatura possibilita a chamada experiência vicária, pois, ao entrarmos em contato com as experiências dos personagens, atravessamos fronteiras desconhecidas de nós mesmos", e nos constitui por essa 
exterioridade. O que implica pensar naquilo que Bakhtin (2011, p. 26) nomeia por excedente de visão, bem como das fronteiras que nos perpassam e também nos constituem a partir desse outro a que nos parece estranho e nos é externo, em determinados contextos sociais e históricos: "[a]ssim, acontece a percepção real; em um mundo exterior-único que eu posso ver, escutar e apalpar, eu não encontro minha expressividade externa enquanto objeto único e igualmente externo, ao lado de outros objetos; eu me encontro numa espécie de fronteira do mundo que vejo[...]".

No capítulo 4, intitulado O Deus da solidão, Karnal (2018, p. 126) instiga o leitor a refletir sobre a maneira como a solidão influenciou/influencia as "maiores religiões e práticas religiosas", ilustrando como Buda, Jesus, Moisés, Maomé, Abraão e José, dentre outros personagens religiosos/bíblicos buscaram e encontraram no isolamento Deus e a si mesmos. Segundo relata Karnal (2018, p. 93) “[...] estar próximo de Deus traz virtude e fartura. Por outro, afastar-se dele traz seca e privação". Os momentos passados embaixo da figueira, como ocorreu com Buda, ou a caminhada solitária no deserto feita por Jesus, implicam, nestes casos, na fé de cada um, naquilo que cada um acredita e traz para si motivos outros para seguir adiante. Razões estas para se auto(conhecer), ser tocado e (trans)formado no/pelo e com isolamento, estar e vivenciar a solidão no/em diálogo com Deus. Deste modo, conforme afirma Karnal (2018, p. 94) “[u]ma solidão sem Deus é algo que não se deseja na tradição”. Isso, pois, a solidão vivenciada, experenciada a partir de algumas passagens bíblicas inscritas no Antigo Testamento e discursivizadas pelo autor, se faz necessária para o desenvolvimento e serve como alimento do espírito, "encontra Jesus a sua essência". O homem encontra, assim, o equilíbrio e a acolhida na/pela palavra da "salvação".

No capítulo 5, intitulado $A$ imagem do solitário: arte e cinema em busca do isolamento imagético, o autor lança um olhar inicial para a conexão que envolve a arte e a solidão com um metatexto. Ou ainda, "com um metatexto sobre um metatexto" (KARNAL, 2018, p. 127). Cita como exemplo a obra "A chama de uma vela", do filósofo e poeta francês Gaston Bachelard. As reflexões engendradas por Bachelard propunham pensar, conforme desenvolve Karnal (2018, p. 127), na relação da solidão de uma vela com outra vela em um dado tempo e espaço, sendo que "[...]mesmo que se juntem duas velas, a chama de uma não se funde à outra". Isso, pois, cada uma à sua maneira, pelas vivências, experiências particulares ou públicas, individuais ou coletivas, são constituídas também pela solidão. A vela, assim como o poeta descrito por Bacherlard, inicia sua trajetória sozinha, "ganha vida própria, luz própria [...], uma simples vela" (KARNAL, 2018, p. 128). Karnal (2018) convida o leitor a fazer essa reflexão, considerando a arte como vela. A vela passa a assumir uma 
posição importante diante da solidão vivida por cada um de nós. Uma vela que traz luz a essa solidão, assim como a arte também passa a iluminar nossa existência. "Quantas vezes um filme, livro, música ou obra qualquer iluminou meandros escondidos de todos nós, locais que nem sequer imaginávamos existir. Pode iluminar e nos transformar por meio dessa luz" (KARNAL, 2018, p. 128).

Dessa forma, assistir a um filme, ler um livro, ouvir uma música nunca é algo pronto, acabado, repetível. Ao contrário, essas ações são praticadas pelas pessoas em tempos e espaços distintos, porque "[c]ada pessoa, individualmente, lê e relê a obra, e, a cada releitura, descobre algo novo" (KARNAL, 2018, p. 130), se descobre, se transforma e transforma o outro nos/pelos diferentes sentidos atribuídos a essa(s) leitura(s). Para enriquecer a discussão, pode-se citar Bakhtin (2011, p. 14), ao enunciar que: “[a]o olharmos para nós mesmos com os olhos do outro, na vida sempre tornamos a voltar para nós mesmos, e o último acontecimento, espécie de resumo, realiza-se em nós nas categorias da nossa própria vida". Esse autor concebe que o sujeito é, nessa perspectiva dialógica, inacabado, em movimento, assim como as leituras que realiza em diferentes esferas da atividade humana (familiar, midiática, religiosa, entre outras) situado histórica e socialmente. E, conforme aponta Karnal (2018, p. 130), "[a] obra nos recria a cada leitura. [...] mudamos, a obra e eu, a cada reencontro"

De todo modo, nunca estamos sós, mesmo que o homem busque, almeje este isolamento imagético nos grandes centros urbanos ou nas/pelas interações midiáticas/digitais. Ou seja, desejar esta "solidão libertadora" que atravessa o século XIX, da sua representação em filmes e obras de arte, é uma "condição para ser livre” (KARNAL, 2018, p. 143). Tal qual aponta o autor, é o poder da luz da vela que traz em certa medida a uma cura e leva as pessoas a se sentirem menos solitárias, adoecerem menos. A arte, assim, tem essa "capacidade de amenizar a solidão, de nos fazer pensar, de nos aproximar e sentir” (KARNAL, 2018, p. 150).

O capítulo 6, intitulado As solitárias, é tecido pelo autor trazendo à baila o termo solidão social, o qual emerge de processos sociais, históricos, culturais, ideológicos, muito bem pontuado no seguinte excerto: “[...] quando a imposição da solidão se torna algo normativo, legal. Punimos com a solitária" (KARNAL, 2018, p. 166). Como punição, ela pode ser aferida ao sistema prisional com o controle do corpo, elegendo assim, um poder disciplinar "o modelo em que concentram todas as tecnologias coercitivas do comportamento" (FOUCAULT, 2014, p. 289). Ou ainda, a solidão descrita pela e na terceira idade, quando muitos idosos acabam sendo alocados pela família ou pelo Estado em hospitais, asilos. Ou, ainda, a solidão vivida no/em matrimônio, a dois, em que "A solidão é cruel", afirma Karnal (2018, p. 151). Assim o é, pois pode causar estragos no ser humano quando 
isolado fisicamente de outro ser. Debilita, enfraquece, mingua os sentimentos e até a essência de quem vive esse isolamento, o da solitária. Assim, concorda-se com o autor e, a partir da uma perspectiva bakhtiniana, pode-se compreender que somos seres sociais, vivemos em dialogia com o outro, somos seres gregários ou congregados que nos fragilizamos a partir do isolamento, carecemos desse afeto, desse cuidado do outro.

Além disso, reforça Karnal (2018, p. 156) que "[e]star sozinho e bem requer maturidade e equilíbrio. Desequilibrados, inseguros e aqueles com vazios impreenchíveis na alma tremem diante da possibilidade de estar sem alguém do lado". Ao se referir à relação conjugal, o autor aponta que a agrura não se configura a partir do ficar/estar sozinho ou ficar/estar em silêncio, mas na falta de diálogo, falta deste encontro de almas. Essa solidão que talvez tivesse uma resolução ou "cura" na dialogicidade com o outro. Contudo, não o é, porque mesmo em companhia, como expõe Karnal (2018), há casais que vivem a sós durante anos de matrimônio. Logo, não é a companhia, mas as relações de afeto, de cuidado, de interação, de diálogo para com o outro e do outro para consigo que faz a solidão não ser tão intensa ou inexistir em alguns contextos sociais. Até porque "[a] solidão é um problema criado pela sociedade" (KARNAL, 2018, p. 158).

Por fim, a conclusão intitulada pelo autor de Solitários do mundo, afastai-vos, baseado no pensamento do poeta francês Jean-Nicolas Arthur Rimbaud, tem como pressuposto que o "Eu é um outro" (KARNAL, 2018, p. 181) e nessa reflexão que realiza com o leitor, Karnal (2018) retoma os diferentes cronotopos $^{5}$ no decorrer de sua obra em que a solidão se configura: solidão-solitude, solidão-experiência, solidão-produtiva, solidão-conectada, solidão da consciência, solidão-idealista, solidão-libertadora, solidão-egoísta, solidão voluntária e/ou forçada, assim como os estranhamentos, encontros, desencontros, descobertas, desafios, achar-se, perder-se, que englobam distintas dimensões de nossa existência.

A partir dos mais variados papéis que enquanto sujeito social e gregário ocupamos e nos situamos no mundo, nas mais variadas esferas sociais da atividade humana, nas e pelas interações dialógicas que realizamos com esse outro, nos constituímos e também constituímos esse outro (BAKHTIN, 2011[1979]). Na voz de Geraldi (2013[1991], p. 6) "os sujeitos se constituem como tais à medida que interagem com os outros, sua consciência e seu

${ }^{5}$ A essa relação entre tempo e espaço que constitui o enunciado, Bakhtin (1998) em "Questões de literatura e estética", vai chamar de cronotopo. "O cronotopo liga-se ao que Bakhtin denomina "grande temporalidade", podendo, portanto, ser conceituado como "a expressão de um grande tempo" (GEGe, 2009, p. 25, grifos do grupo). Enquanto o espaço é social, o tempo é histórico, pois é a dimensão do movimento no campo das transformações e dos acontecimentos" (GEGe, 2009, p. 25, grifos do grupo). Amorin (2018, p. 105) complementa que "[o] conceito de cronotopo trata de uma produção da história. Designa um lugar coletivo, espécie de matriz espaço-temporal de onde as várias histórias se contam ou se escrevem. Está ligado aos gêneros e a sua trajetória". 
conhecimento de mundo resultam como "produto" desse mesmo processo". Processo este do qual agimos, nos movemos e existimos em grupo, congregados na/pela relação com outro.

Assim, a "solidão é lugar privilegiado para distinguir vozes do mundo, incluindo as que me definiram e eu incorporei” (KARNAL, 2018, p. 186) nos/pelos vínculos de alteridade, ou seja, na/pela nossa conexão dialógica com o outro, ou seja, “[a] interação com o outro é a condição da possibilidade de existência e constituição do sujeito como ser social", histórico e perpassado por ideologias (SILVEIRA; ROHLING, RODRIGUES, 2012, p. 19). Portanto, o que nos identifica, nos constitui ser quem somos é o "resultado histórico das relações com os outros sujeitos" (SILVEIRA; ROHLING, RODRIGUES, 2012, p. 19). As pessoas se complementam e se completam em um processo que se dá continuamente com/no e pelo outro. É preciso deixar-se, permitir-se ouvir para deixar "emergir o outro" (KARNAL, 2018, p. 186), um “outro em si” (KARNAL, 2018, p. 187).

\section{REFERÊNCIAS}

AMORIN, M. Cronotopo e exotopia. In: BRAIT, B. (org.). Bakhtin: outros conceitos-chave. 2. ed. 3. reimp. São Paulo: Contexto, 2018. p. 95-114.

BAKHTIN, M. M. Questões de literatura e de estética: a teoria do romance. Trad. Aurora Fononi Bernardini et al. São Paulo: Ed. da Unesp: Hucitec, 1998.

BAKHTIN, M. M. Estética da criação verbal. Tradu. Paulo Bezerra. 6. ed. São Paulo: Martins Fontes, 2011.

BAKHTIN, M. M. Marxismo e filosofia da linguagem: problemas fundamentais do método sociológico na ciência da linguagem. Trad. Sheila Grillo e Ekaterina Vólkova Américo. São Paulo: Editora 34, 2017.

CORTELLA, M. S. Não se desespere: provocações filosóficas. 7. ed. Petrópolis, RJ: Vozes, 2014.

FOUCAULT, M. Vigiar e Punir: nascimento da prisão. Trad. Raquel Ramalhete. 42. ed. Petrópolis, RJ: Vozes, 2014.

GEGE. Grupo de estudos dos Gêneros do Discurso. Palavras e contrapalavras:

Glossariando conceitos, categorias e noções de Bakhtin. São Carlos: Pedro \& João Editores, 2009.

GERALDI, J. W. Portos de Passagem. 5. ed. São Paulo: Martins Fontes, 2013.

KARNAL, L. O dilema do porco-espinho: como encarar a solidão. 2. ed. São Paulo: Planeta do Brasil, 2018. 
PRENSKY, M. Digital Natives Digital Immigrants. On the Horizon, NCB University Press, v. 9, n. 5, out. 2001. Disponível em: https://www.marcprensky.com/writing/Prensky\%20\%20Digital\%20Natives,\%20Digital\%20Immigrants\%20-\%20Part1.pdf. Acesso em: 2 set. 2020.

SILVEIRA, A. P. K.; ROHLING, N.; RODRIGUES, R. H. A análise dialógica dos gêneros do discurso e os estudos do letramento: glossário para leitores iniciantes. Florianópolis: DIOESC, 2012.

\section{Como referenciar este artigo}

POTTMEIER, S.; FISTAROL, C. F.; CAETANO, M. H. C.; DONIDA, L. O. O dilema do porco-espinho: como encarar a solidão. Rev. Sem Aspas, Araraquara, v. 9, n. 1, p. 170-178, jan./jun., 2020. e-ISSN: 2358-4238. DOI: https://doi.org/10.29373/sas.v9i1.14127

Submetido em: $10 / 07 / 2020$

Aprovado em: $18 / 09 / 2020$

Publicado em: 30/09/2020 